\title{
Overcoming Geoinformatic Knowledge Fence: An Exploratory of Intelligent Geospatial Data Preparation within Spatial Analysis
}

\author{
Jian Wang ${ }^{1}$, Chun-jiang Zhao ${ }^{1, *}$, Fang-qu Niu ${ }^{2}$, and Zhi-qiang Wang $^{2}$ \\ ${ }^{1}$ National Engineering Research Center for Information Technology in Agriculture \\ (NERCITA), Beijing 100097, China \\ Zhaocj@nercita.org.cn \\ ${ }^{2}$ Institute of Geography Sciences and Natural Resources Research, \\ Chinese Academy of Sciences, Beijing 100060 China \\ Wangj@nercita.org.cn
}

\begin{abstract}
The booming of earth observation provides decision-makers with more available geospatial data as well as more puzzles about how to understand, evaluate, search, process, and utilize those overwhelming resources. The paper distinguishes a concept termed geoinformatic knowledge fence (GeoKF) to discuss the knowledge-aspect of such puzzles and the approach to overcoming them. Basing on analysis of the gap between common geography sense and geoinformatic professional knowledge, the approach composes analysis space modeling and spatial reasoning to match decision models to the online geospatial data sources they need. Such approach enables automatically and intelligently searching of suitable geospatial data resources and calculating their suitability to given spatial decision and analysis. An experiment with geoservices, geo-ontology and rule-based reasoning (Jess) is developed to illustrate the feasibility of the approach in scenario of data preparation within decisions of bird flu control.
\end{abstract}

Keywords: spatial decision support, geo-ontology, spatial reasoning, geoservices, geography information metadata.

\section{Introduction}

With booming of earth observation and other earth-related activities, there is a dramatically increase of types and volume of available geospatial data in form of online data set and services. Companying with such overwhelming data, users, esp. those without enough geoinformatic knowledge (termed here as n-geo users), find it more difficult to understand and utilize those dazzling resources [1-3]. Most difficulties can finally find the root to insufficiency of geoinformatic knowledge (such as those relating to temporal-spatio scale or precision) and so are defined here as geoinformatic knowledge fence (GeoKF). With continually increasing of available geospatial data, GeoKF will

\footnotetext{
${ }^{*}$ Corresponding author.
} 
become an important obstacle to earth observation application, geospatial information services and other geocomputing applications.

The experiment is an exploratory to overcome GeoKF by combining geoinformatic knowledge with computing reasoning in scenario of geospatial data preparation within spatial decision making. Five sections are laid out in the paper. Section 1 introduces and defines GeoKF, then section 2 explains the philosophy and conceptual model of the approach to overcoming GeoKF. In section 3 the design of experiment system is detailed following the conceptual model, the experiment result is analyzed in the same section. Finally there are a discussion (section 4) and a conclusion (section 5) at the end of the paper.

\section{Philosophy and Conceptual Model of GeoKF Overcoming}

\subsection{Philosophy of GeoKF Overcoming}

A questionnaire on 30 n-geo experts (mainly in agriculture engineering, information system and management) of NERCITA shows two sorts of geographic knowledge during their spatial analysis. One can be termed as common geographic sense (CGS) mainly by which people model their analysis space through assigning i.e. spatiotemporal domain, scale and precision, etc.; the other can be termed as geoinformatic professional knowledge (GPK) by which geoinformatic professionals can understand various geospatial data and utilize them in a more effective and suitable way, for example processing some ostensibly unsuitable data by generalization or scale transformation to meet spatial analysis. Most n-geo experts lack the later and so are prevented from efficiently geospatial data preparation within their spatial analysis.

The research philosophy comes from the knowledge-oriented analysis of GeoKF and spatial decision process (Fig.1). GeoKF roots from knowledge heterogeneity between n-geo users and geoinformatic professionals, and can be represented as a fence between CGS and GPK. CGS, together with domain knowledge, is generally employed by domain professionals (most are n-geo users) to construct space model of analysis (SMoA) within which the target objects or processes are modeled and analyzed [4]. Such models also determine the suitable geospatial data for analysis, namely, record the data requirements (both data sources and their properties) in form of CGS. On the other side, various geospatial data is traditionally described and represented by their GPK-based metadata in terms of i.e. FGDC. So GeoKF-overcoming practically means the mapping between SMoA and GPK-based metadata, which generally perform by cooperation of geoinformatic professionals and n-geo SMoA makers.

The paper aims to find an intelligent and automatic approach to replacing the cooperation by spatial reasoning. Specifically, the paper aims to verify two hypothesizes below.

- Hyp. \#1. CGS can be regarded as dialect subsets of GPK, which means the data requirements of CGS-based SMoA can be 'translated' into GPK-based description of geospatial data. The translation gives the possibility of spatial reasoning to match SMoA and the data it need.

- Hyp. \#2. Current GPK-based metadata can be modified or extended to support spatial reasoning relating to down or up-scaling, precision transform, etc. 


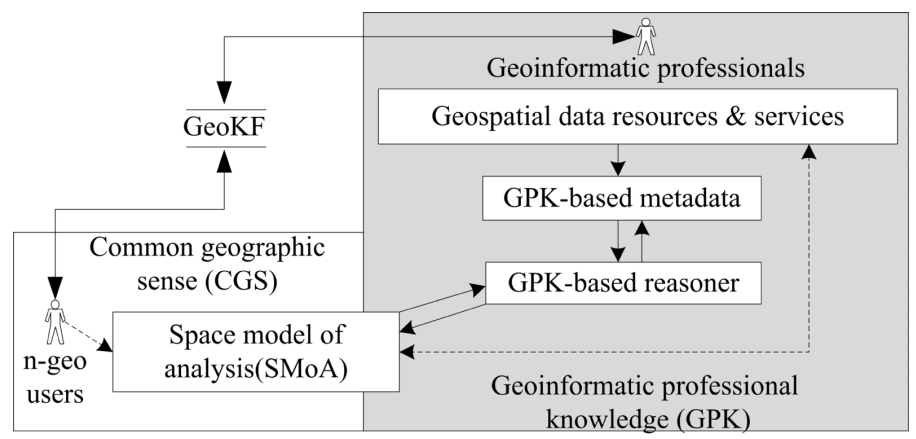

Fig. 1. GeoKF-overcoming philosophy

\subsection{Conceptual Model}

Space Model of Analysis. From the perspective of n-geo users, each spatial analysis task has its space models, which contain all analyzed geography features within certain spatial and temporal domain. The model can be expressed by a triple of (features, space, time). Features can be further expressed as (focal features, background features). Focal features are those analyzed such as roads in transport analysis; background features are those that function as context of focal features such as land use in transport analysis. Each dimension (space or time) is identified by domain, scale and precision. Although some geoinformatic professionals suggest that scale covers precision [5-7], most n-geo users are apt to confuse them and so the research employs both concepts contemporarily. Scale here means the size of analyzed or sampled unit. Precision here refers to minimum certain measure value of analysis. By this way, space dimension is the triple of (spatial domain, spatial scale, spatial precision), while time dimension is another triple of (temporal domain, temporal scale, temporal precision).

Table 1. Some main fundamental ontology

\begin{tabular}{ll}
\hline Fundamental ontology & Description \\
\hline $\begin{array}{l}\text { Geospatial theme-feature } \\
\text { ontology }\end{array}$ & $\begin{array}{l}\text { Extended ISO 19115[9], one example of extension are poultry } \\
\text { feature of agriculture theme. }\end{array}$ \\
$\begin{array}{l}\text { Geospatial scale and } \\
\text { precision ontology }\end{array}$ & $\begin{array}{l}\text { Describing the knowledge of geospatial scale and precision, } \\
\text { including, metric scale (i.e. mapping scale, traditional airphoto } \\
\text { scale, etc.), named scale (Global scale, continent scale, region }\end{array}$ \\
& $\begin{array}{l}\text { scale etc.), and precision. } \\
\text { Describing the knowledge of geospatial domain, including } \\
\text { named domain (government precinct, geology zoning, } \\
\text { ontology }\end{array}$ \\
$\begin{array}{l}\text { geography zoning, etc.) } \\
\text { Time scale and precision } \\
\text { ontology }\end{array}$ & $\begin{array}{l}\text { Describing the knowledge of time scale and precision, includ- } \\
\text { ing metric scale (second, day, year, etc.), named scale (Macro }\end{array}$ \\
& $\begin{array}{l}\text { scale, geography scale, etc.), and precision (second, minute,..., } \\
\text { year, etc.) } \\
\text { Describing temporal domain, including named domain } \\
\text { (geology, geography, etc.) }\end{array}$ \\
\hline $\begin{array}{l}\text { Temporal domain } \\
\text { ontology }\end{array}$ &
\end{tabular}


Knowledge Organization and Reasoning. All knowledge (CGS \& GPK) should be organized in computable formats such as ontology, knowledge base with facts and rules[8], etc. The organization should consider both computing (i.e. spatial reasoning) and human operating. Some main fundamental knowledge is listed in Tab. 1 in form of ontology.

Spatial Reasoning. The spatial reasoning (Fig. 2) combines human intelligence and computing reasoning by an iteration cycle consisting of 1) rendering data requirements of SMoA to GPK-based reasoner, 2) reasoning and suitability calculating basing on data requirements, GPK, and metadata, and 3) returning result to n-geo users, who can re-render or accept result to end current cycle. Each cycle consists of three sub-reasoning tasks (theme-ontology evaluation, space evaluation, and time evaluation). Each task reasons on a section of SMoA requirement, corresponding knowledge base (represented as ontology in Fig.) and metadata of evaluated geospatial data source. The performance of each task will return the section suitability of current geospatial metadata. GPK-based resoner controls the running of sub-task and calculates the whole suitability of evaluated geospatial data sources by scanning metadata list of them. Formula (1) is used to calculate the suitability index $(S I)$, while some GPK-based reasoning rules are listed in Tab.2.

$$
S I=\sum\left((\text { suitability-item })_{i} \times W_{i}\right)(i=1, \ldots m)
$$
data.

SI: suitability index, the final suitability value of evaluated geospatial

(Suitability-item $)_{i}$ : the result of evaluating of certain $(i)$ items of SMoA.

$W_{i}$ : the weight of each items of SMoA. The valued is appointed by decision makers to assign the importance of items. The total of all weight is $100 \%$.

$m$ : the number of evaluated items of SMoA.

Table 2. Main rules for suitability reasoning and calculation

\begin{tabular}{|c|c|c|}
\hline Items of SMoA & Suitability-item & Description \\
\hline Feature & $M / N \times 100 \%$ & $\begin{array}{l}N: \text { the number of expected features in SMoA } \\
M: \text { the number of existence features of evaluated } \\
\text { geospatial data }\end{array}$ \\
\hline Space-Domain & $\begin{array}{l}(\text { SMoA-D/Data- } \\
D) \times 100 \%(0-100 \%)\end{array}$ & $\begin{array}{l}\text { SMoA-D: the domain of spatial analysis } \\
\text { Data-D: the domain of evaluated geospatial data }\end{array}$ \\
\hline $\begin{array}{l}\text { Space-Scale \& } \\
\text { Time-scale }\end{array}$ & $0 \%, 100 \%$ & $\begin{array}{l}100 \% \text { : the scale of evaluated geospatial data is } \\
\text { equal directly or by upscaling. } \\
0 \% \text { : other occasions }\end{array}$ \\
\hline $\begin{array}{l}\text { Space-Precision } \\
\& \\
\text { Time-Precision }\end{array}$ & $0 \%, 100 \%$ & $\begin{array}{l}100 \% \text { : the precision of evaluated geospatial data } \\
\text { directly or more precise to SMoA. } \\
0 \% \text { : other occasions }\end{array}$ \\
\hline Time-domain & $0 \%, 100 \%$ & $\begin{array}{l}100 \% \text { : the time period of evaluated data content } \\
\text { can cover time of SMoA completely } \\
0 \% \text { : other occasions }\end{array}$ \\
\hline
\end{tabular}




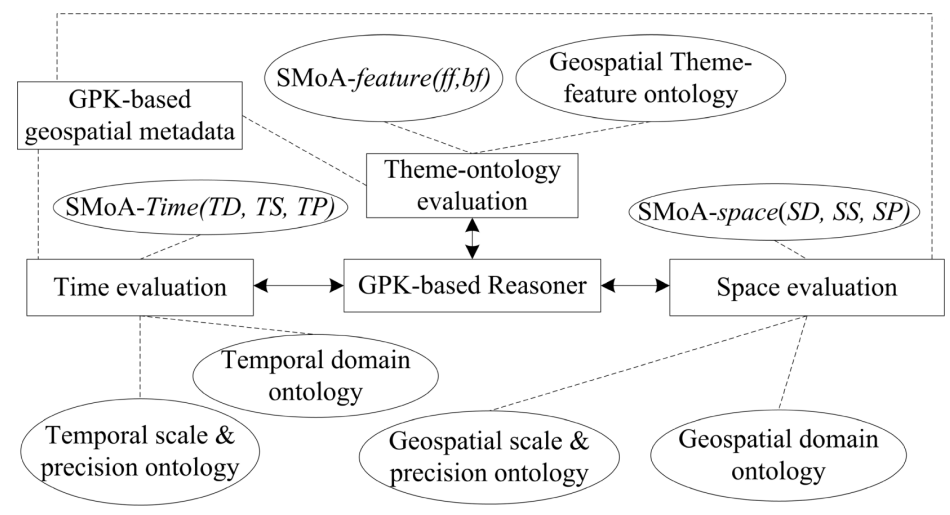

Fig. 2. Spatial reasoning

Conceptual Model. The model have 5 key components including geospatial data source agent, n-geo users and geoinformatic professionals, knowledge base (facts and rules), GPK-based reasoner, and human-computer interface (Fig.3). Geospatial data sources agent functions as a list of enrolled GPK-based metadata (Tab.3) of online

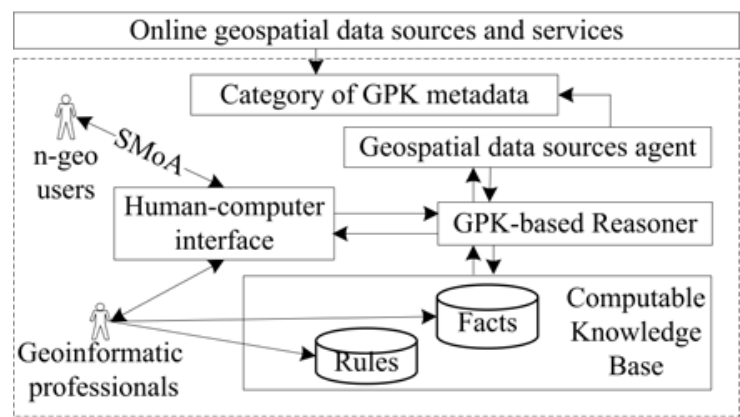

Fig. 3. Conceptual Model

Table 3. GPK-based FGDC metadata (limited to extended or modified items only)

\begin{tabular}{|c|c|c|}
\hline FGDC metadata item & $\begin{array}{l}\text { Extended or modified } \\
\text { metadata Items }\end{array}$ & Description of extension or changes \\
\hline $\begin{array}{l}\text { Entity \& Attributes and } \\
\text { Keyword-Theme }\end{array}$ & Theme-features & $\begin{array}{l}\text { Bounding Entities to Theme-feature } \\
\text { ontology }\end{array}$ \\
\hline $\begin{array}{l}\text { Identification-spatial } \\
\text { domain }\end{array}$ & Spatial domain & $\begin{array}{l}\text { Bounding to geospatial domain } \\
\text { ontology }\end{array}$ \\
\hline Null & Spatial Scale & $\begin{array}{l}\text { Bounding to geospatial scale \& } \\
\text { precision ontology }\end{array}$ \\
\hline Null & Temporal scale & $\begin{array}{l}\text { Bounding to temporal scale \& } \\
\text { precision ontology }\end{array}$ \\
\hline
\end{tabular}


geospatial data sources. CGS and GPK are organized in computable knowledge base for GPKreasoning. Human-computer interface is a GUI web page that lets decision makers (mainly n-geo users) render (and re-render) their SMoA as well as check the suitability of reasoned results.

\section{Experiment Design and Analysis}

An experiment, with a software system as its core, is designed and implemented to check the feasibility of philosophy. The comparison of reasoned results with evaluation of both n-geo users and geoinformatics professionals is employed as the basic method for the verification.

\subsection{Experiment Design}

The experiment is a simplified spatial decision support of bird flu control in an agriintensive county of Beijing area. Three independent and geographically distributed government agencies, which hold different geospatial and agricultural data sources, will collaborate with their data sources. The spatial analysis aims to zone epidemic impacted area and set block stations to control epidemic diffusion. Some main items of SMoA of the decision are listed in Tab.4. The available online geospatial data can be seen in Tab.5.

Table 4. SMoA items of bird flu control decision

\begin{tabular}{|c|c|c|}
\hline SMoA items & Value & Description \\
\hline Feature-focal & $\begin{array}{llll}\begin{array}{l}\text { Poultry } \\
\text { agriculture }\end{array} & \text { livestock } & - \\
\end{array}$ & $\begin{array}{l}\text { From geospatial theme-feature } \\
\text { ontology }\end{array}$ \\
\hline Feature-background & Roads-Transportation & $\begin{array}{l}\text { From geospatial theme-feature } \\
\text { ontology }\end{array}$ \\
\hline Feature-background & $\begin{array}{l}\text { Resident area - land use - } \\
\text { plan }\end{array}$ & $\begin{array}{l}\text { From geospatial theme-feature } \\
\text { ontology }\end{array}$ \\
\hline Feature-background & $\begin{array}{l}\text { Government precinct - } \\
\text { named domain }\end{array}$ & From Geospatial domain ontology \\
\hline Space-domain & $\begin{array}{l}\text { Daxing District-Beijing } \\
\text { city-China-Government } \\
\text { precinct-Named domain }\end{array}$ & From geospatial domain ontology \\
\hline Space-Scale & $\begin{array}{l}\text { 1:10000, Mapping scale- } \\
\text { metric scale }\end{array}$ & $\begin{array}{l}\text { From geospatial scale \& precision } \\
\text { ontology }\end{array}$ \\
\hline Space-Precision & $100 \mathrm{M}-$ precision & $\begin{array}{l}\text { From geospatial scale \& precision } \\
\text { ontology }\end{array}$ \\
\hline Time-domain & after. 2004 & Null \\
\hline Time-scale & Year-metric scale & $\begin{array}{l}\text { From Temporal scale \& precision } \\
\text { ontology }\end{array}$ \\
\hline Time-precision & Null & Null \\
\hline
\end{tabular}


Software System Design. As an experiment prototype, the system adopts Jess and Rete algorithm [8] because that Jess is a classic and fundamental technology for knowledge organization and reasoning. Ontology, and other knowledge technologies, is only used to organize knowledge to apart the proposed philosophy from implementation technologies as possible as it can. The logic structure of software system is listed in Fig 4.

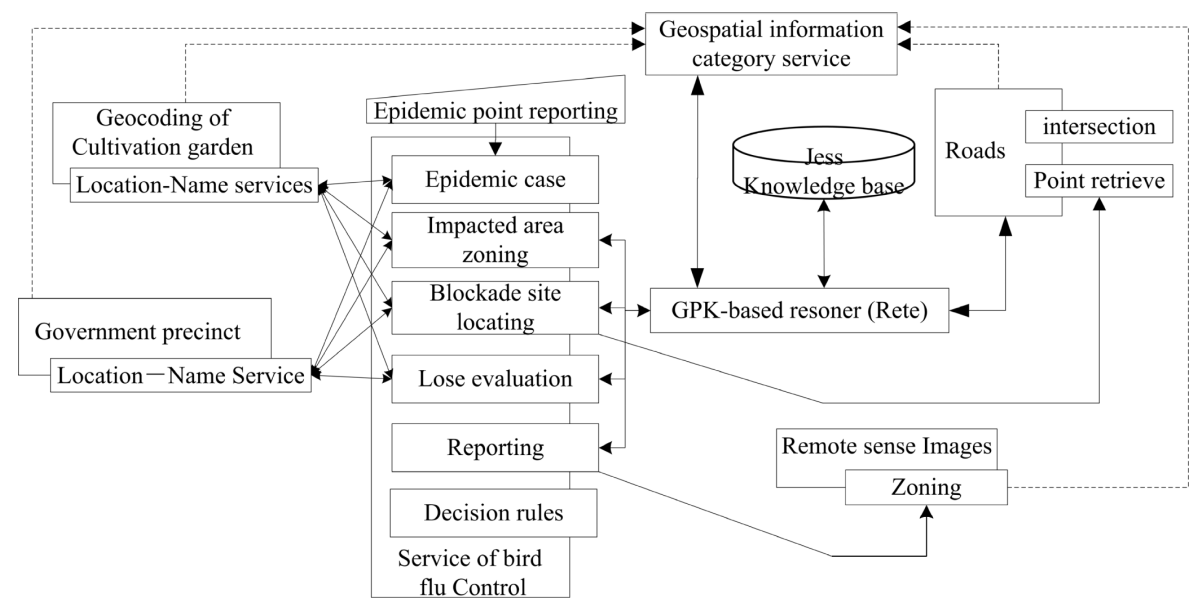

Fig. 4. The system is an implementation (with 7 web services and 13 endpoints) of conceptual model (Fig.3). The service geocoding of cultivation garden, government precinct, roads, and remote sense images are all online geospatial data services and enrolled into geospatial information category service. The service of bird flu control is an application service (with a GUI page) that performs the spatial analysis trigged by a geo-referenced epidemic point reporting. The endpoint of epidemic case will initialize the spatial analysis of bird flu control as well as construct general SMoA basing on epidemic report. The endpoint of impacted area zoning, blockade site locating, lose evaluation and reporting will undertake the spatial analysis within which their detailed SMoA will be constructed basing on general SMoA and then its requirements will be transported o GPK-based reasoner for obtaining the suitable geospatial data sources. The reasoner will return reasoned result to corresponding endpoint for refining if needed.

\subsection{Result and Analysis}

Tab. 5 shows the comparison of reasoned results with human evaluation. Such comparison displays a generally consistence between reasoned results and expert evaluations, which can preliminarily give feasibility for further research. While as a philosophy-proof experiment, there still exist many defects such as small sample of online geospatial data, relatively simple reasoning rules (esp. on scale down- and upscaling and precision, etc.) and facts, etc. Additionally, a strong suggestion from experts for further research is to add quality of data services (QoS) into SMoA and GPK-reasoning to get dynamic optimal data set. 
Table 5. Comparison of human evaluation with reasoned result

\begin{tabular}{|c|c|c|c|c|c|c|c|c|c|c|}
\hline \multirow{4}{*}{$\begin{array}{l}\text { Available } \\
\text { geospatial } \\
\text { data }\end{array}$} & \multirow{4}{*}{$\begin{array}{l}\text { Human } \\
\text { evaluation } \\
\text { of } \\
\text { suitability }\end{array}$} & \multicolumn{9}{|c|}{ Reasoned suitability index $(\%)$} \\
\hline & & \multirow[t]{3}{*}{ total } & \multicolumn{2}{|c|}{ Feature $\%$} & \multicolumn{3}{|c|}{ Space } & \multicolumn{3}{|l|}{ Time } \\
\hline & & & $\overline{F F}$ & $\mathrm{BF}$ & SD & SS & SP & TD & TS & TP \\
\hline & & & $30 \%$ & $5 \%$ & $30 \%$ & $10 \%$ & $5 \%$ & $10 \%$ & $5 \%$ & $5 \%$ \\
\hline $\begin{array}{l}\text { Cultivation } \\
\text { garden } \\
(2004)\end{array}$ & High & 95 & 100 & 0 & 100 & 100 & 100 & 100 & 100 & 100 \\
\hline $\begin{array}{l}\text { Fundamental } \\
\text { geography } \\
\text { information } \\
(2000 \text { : } \\
1: 10 \mathrm{M})\end{array}$ & Mid & 85 & 50 & 100 & 100 & 100 & 100 & 100 & 100 & 100 \\
\hline $\begin{array}{l}\text { Beijing } \\
\text { fundamental } \\
\text { geography } \\
\text { informa- } \\
\text { tion(1998 } \\
\text { 1:10000) }\end{array}$ & High & 75 & 50 & 100 & 100 & 100 & 100 & 0 & 100 & 100 \\
\hline $\begin{array}{l}\text { Beijing } \\
\text { Quickbird } \\
\text { image (2008- } \\
12: \\
R=0.61 \mathrm{M})\end{array}$ & High & 100 & 100 & 100 & 100 & 100 & 100 & 100 & 100 & 100 \\
\hline $\begin{array}{l}\text { Beijing DEM } \\
(1: 10000, \\
2001)\end{array}$ & Low & 0 & 0 & 0 & 100 & Null & Null & Null & Null & Null \\
\hline $\begin{array}{l}\text { Beijing } \\
\text { MODIS } \\
(2008-12 \\
30 \mathrm{M})\end{array}$ & Mid & 70 & 50 & 100 & 100 & 0 & 0 & 100 & 100 & 100 \\
\hline
\end{tabular}

\section{Discussion}

According to the exploratory research, GeoKF-overcoming is a synthetic issue relating to some traditional geocomputing problems including intelligent geospatial data generalization [10-11], scale and precision transformation [12], etc. In other words, GeoKF research will depend on and contribute to those relating studies. Such relationships among them also discover some features of further researches.

- The combination of artificial and human intelligence. Because of the immature of scale transform, automatically geospatial data generalization and other relative issues, the overcoming of GeoKF is still a combination of human and computing intelligence, namely, increasing the level of automation by adding more knowledge and reasoning ability is a key research direction.

- The dependence of GeoKF-overcoming practice on fundamental GPK research and practices. Although more and more discussions of geo-ontology or other geoknowledge relative researches appear recently, the practice works, such as construction 
of geo-ontology (including geospatial theme-feature ontology, geospatial scale \& precision ontology, etc.), have not yet functioned. Furthermore, the workings relating to geo-knowledge components, such as adding more semantic to metadata to support computing reasoning, are still in their way to practice. It is clear that the power of proposed approach of the paper will grow with increase of those workings.

\section{Conclusion}

With booming of available online geospatial data resources, the bottleneck of net-centric geocomputing has moved gradually from network and computing capability to efficiently utilization of data resources by more users, esp. n-geo users. As a consequence, geoinformatic knowledge and intelligent geo-computing (including geoontology, spatial reasoning, intelligent generalization of geospatial data, etc.) has been attracting increasing attentions when facing overwhelming online resources.

The research suggests that GeoKF is an emerging issue within intelligent geo-computing. It shares one aim of geo-cognition research, namely, how to provide n-geo users with correct understanding and utilization of dazzling online geospatial data sources, as well as to help geoinformatic professionals improve their efficiency and capability. Featuring with knowledge-oriented analysis of geospatial data process and spatial analysis, the conceptual model with SMoA, GPK-based reasoning and extended GPK metadata, and the combination of human and computing intelligence, the proposed approach shows its feasibility for further research of GeoKF.

Acknowledgments. The paper is supported by Beijing sci-tech Nova plan (2006B27) and national key technology R\&D program (2006BAJ05A09, 2006BAD10A05).

\section{References}

1. Rahimi, S., Cobb, M., Ali, D., Paprzycki, M., Petry, F.E.: A knowledge-based multi-agent system for geospatial data conflation. Journal of Geographic Information and Decision Analysis, 1480-8943 (2002)

2. Wei, Y., Yue, P., Dadi, U., Min, M., Hu, C., Di, L.: Effective Acquisition of Geospatial Data Products in a Collaborative Grid Environment. In: IEEE International Conference on Services Computing (SCC 2006), pp. 455-462. IEEE Press, New York (2006)

3. McMaster, R.B., Lynn, E.: A Research Agenda for Geographic Information Science. CRC Press, Boca Raton (2004)

4. Longley, P., Batty, M.: Advanced Spatial Analysis. ESRI Press, Redlands (2003)

5. zhilin, L.: A theoretic discussion on the scale issues in geospatial data handling. J. Geomatics world, $1-5$

6. Sun, q.-x., Li, m.-t., Lu, j.-x., Guo, d., Fang, t.: Scale issue and its research progress of geospatial data. J. Geography and geo-information science 23, 5-56 (2007)

7. Meng, b., Wang, j.-f.: A review on the methodology of scaling with Geo-data. J. ACTA geographic SINICA 60(2), 277-288 (2005)

8. Friedman-Hill, E.: Jess in Action: Java Rule-Based Systems. Manning Publications Co. (2003)

9. ISO/TC211 19115: Geographic information - Metadata (2003) 
10. Lehto, L., Sarjakoski, L.T.: Real-time generalization of XML-encoded spatial data for the Web and mobile devices. J. Geographical information science 19(8,9), 957-973 (2005)

11. Jones, C.B., Abdelmoty, A.I., Lonergan, M.E., van der Poorten, P., Zhou, S.: Multi-scale spatial database design for online generalisation. In: Proceedings of the Spatial Data Handling Symposium, Beijing, pp. 7b.34-7b.44 (2000)

12. Li, S.-1., Cai, y.-1.: Some scaling issues of geography. J. Geographical research 1, 11-18 (2005) 